\title{
Successful Treatment of Pure Red Cell Aplasia with Rituximab in Patients after ABO-Compatible Allogeneic Hematopoietic Stem Cell Transplantation
}

\author{
Sung-Hoon Jung Jae-Sook Ahn Deok-Hwan Yang \\ Hyung Chul Park Soo-Young Bae Yeo-Kyeoung Kim \\ Hyeoung-Joon Kim Je-Jung Lee \\ Department of Hematology-Oncology, Chonnam National University Hwasun \\ Hospital, Hwasun, Republic of Korea
}

\section{Key Words}

Pure red cell aplasia - Allogeneic stem cell transplantation - Rituximab - ABO compatibility

\begin{abstract}
Pure red cell aplasia (PRCA) following allogeneic hematopoietic stem cell transplantation (HSCT) has been mostly reported in situations involving major ABO incompatibility between donor and recipient. Conventional treatments such as plasma exchange, erythropoietin, and steroid are often unsatisfactory. Rituximab has been reported to be highly effective for PRCA following major ABO-incompatible allogeneic HSCT. A 49-year-old woman with PRCA following $\mathrm{ABO}$-matched allogeneic HSCT for acute lymphoblastic leukemia, refractory to erythropoietin treatment, received 4 doses of rituximab $375 \mathrm{mg} / \mathrm{m}^{2}$ weekly. After the $3 \mathrm{rd}$ dose of rituximab, she exhibited a striking rise in her reticulocyte count with an increase in her hemoglobin level. To our knowledge, this is the first case of PRCA following major ABOcompatible allogeneic HSCT resolving completely after rituximab treatment.
\end{abstract}




\section{Introduction}

Pure red cell anemia (PRCA) is a syndrome characterized by severe normocytic anemia, reticulocytopenia, and an absence of erythroblasts from an otherwise normal bone marrow [1]. PRCA may appear as a congenital disorder or occur as an acquired syndrome. The acquired form of PRCA may present as a primary hematologic disorder in the absence of any other diseases, or secondary to various underlying diseases including parvovirus B19 infection, large granular lymphocyte (LGL) leukemia and other lymphoproliferative disorders, thymoma, autoimmune disease, the use of offensive drugs, and allogeneic hematopoietic stem cell transplantation (HSCT) [2].

Previously, PRCA following allogeneic HSCT has been reported in patients after ABOincompatible allogeneic HSCT. Here, we describe the first case of PRCA, to our knowledge, following major ABO-compatible allogeneic HSCT for acute lymphoblastic leukemia (ALL) resolving completely after rituximab treatment.

\section{Case Report}

A 49-year-old woman with ALL underwent HLA-matched related allogeneic HSCT (containing $2.2 \times$ $10^{6} \mathrm{CD} 34^{+}$cells $/ \mathrm{kg}$ ) on December 23, 2009. There were no major ABO-mismatch blood types between the donor $\left(\mathrm{O}^{+}\right)$and the recipient $\left(\mathrm{O}^{+}\right)$. The duration from transplantation to an absolute neutrophil count $>0.5 \times 10^{9} / \mathrm{l}$ and to a platelet count $>20 \times 10^{9} / \mathrm{l}$ was 14 and 17 days. Engraftment was confirmed by a bone marrow aspirate and biopsy on day +23 . On day +265 , she showed elevated aspartate transaminase (AST) and alanine transaminase (ALT), and chronic graft-versus-host disease (GVHD) was confirmed by a liver biopsy. She was treated with prednisolone and mycophenolate mofetil. Her liver enzyme levels then normalized. The prednisolone and mycophenolate mofetil were subsequently tapered to 5 and $500 \mathrm{mg}$ on day +452 . There was no regular requirement of packed red cell (PRC) until then. On day +475 , the patient's hemoglobin level suddenly decreased from $10.3 \mathrm{~g} / \mathrm{dl}$ to $6.7 \mathrm{~g} / \mathrm{dl}$. She showed no evidence of GVHD and hemolysis. We started erythropoietin treatment (darbepoetin- $\alpha$ $120 \mu \mathrm{g}$ once weekly) on day +492 , but there was no improvement in her anemia. A bone marrow biopsy was performed on day +545 and revealed a decreased erythroid series without abnormal findings of other cell components, showing a consistent finding of PRCA. In addition, we checked for parvovirus B19 and cytomegalovirus, and there was no evidence of viral infections. We started rituximab $375 \mathrm{mg} / \mathrm{m}^{2}$ once weekly for four weeks starting on day +566 . On day +587 , hemoglobin and reticulocyte began to rise from $6.7 \mathrm{~g} / \mathrm{dl}$ and $0.4 \%(12,000 / \mu \mathrm{l})$ to $9.6 \mathrm{~g} / \mathrm{dl}$ and $4.44 \%(150,500 / \mu \mathrm{l})$ (fig. 1). There were no adverse reactions to rituximab treatment. Currently (on day +732 ), the patient has no transfusion requirement and her hemoglobin level has remained as high as $13.2 \mathrm{~g} / \mathrm{dl}$.

\section{Discussion}

PRCA following allogeneic HSCT has been mostly reported in situations involving major $\mathrm{ABO}$ incompatibility between donor and recipient $[3,4]$, with the exception of one case following major ABO-matched allogeneic HSCT [5]. PRCA following ABOincompatible allogeneic HSCT is associated with an interaction of recipient anti-A or anti-B isoagglutinins with donor erythroid precursors expressing $A$ and/or B antigens [6]. Spontaneous remission has been noted but treatments such as plasma exchange, donor-derived leukocyte infusion, erythropoietin, and steroids may be necessary to avoid RBC transfusion and to decrease the risk of hemochromatosis [7-11].

The mechanism of PRCA following major ABO-matched allogeneic HSCT is unclear. In the case report by Roychowdhury and Linker [5], it is speculated that immune- 
mediated etiology such as the adoptive transfer of autoimmunity or antibodies to erythroid progenitors resulted in PRCA. In addition, non-ABO antigens may be involved in PRCA following allogeneic HSCT.

Our case was analyzed following allogeneic HSCT between a major ABO-matched donor-recipient pair. We found no evidence of infections, hemolysis, and causative medications. The treatment with erythropoietin showed no improvement. Rituximab is a humanized, murine, monoclonal antibody directed against the CD20 antigen, expressed on pre-B lymphocytes and on mature B lymphocytes [12]. Rituximab has been showed to be highly effective for immune-mediated PRCA, autoimmune cytopenias, and PRCA following ABO-incompatible allogeneic HSCT [13-15]. We started rituximab $375 \mathrm{mg} / \mathrm{m}^{2}$ once weekly for four weeks. After the third anti-CD20 monoclonal antibody infusion, the patient exhibited a striking rise in her reticulocyte count, and then had a progressive increase in her hemoglobin level.

To our knowledge, this is the first report of rituximab use for the treatment of PRCA following major ABO-matched allogeneic HSCT. Rituximab seems to be a promising therapeutic option for patients with PRCA following ABO-matched and ABOmismatched allogeneic HSCT.

\section{Disclosure Statement}

The authors have no financial conflicts of interest.

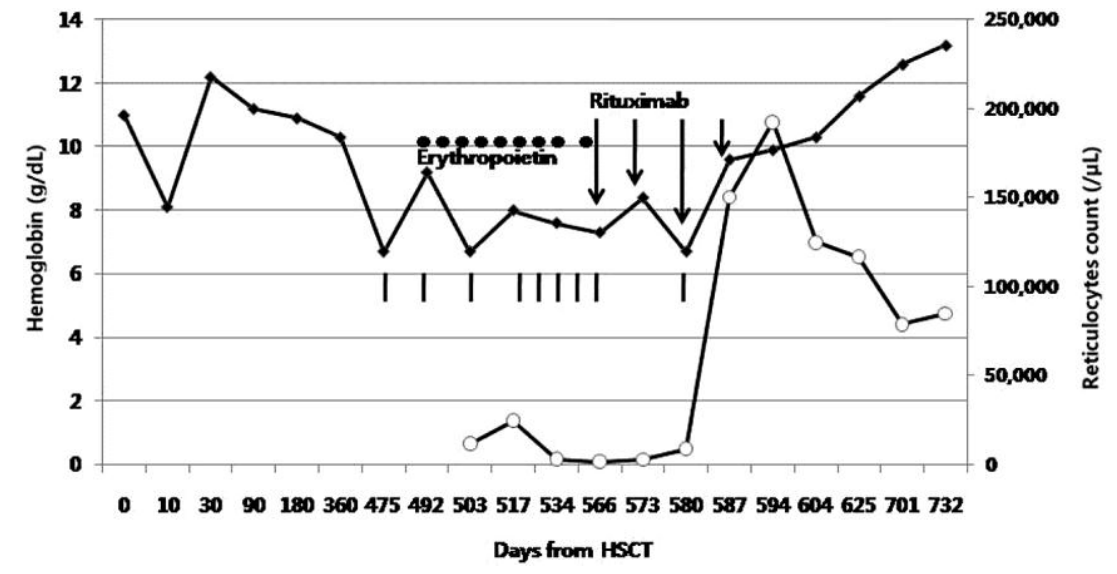

Fig. 1. Clinical course and changes in hemoglobin (black diamonds) and reticulocyte counts (open circles). The arrows show the four seperate infusions of the anti-CD20 monoclonal antibody. The black circles represent erythropoietin injections and the black bars represent packed red cell transfusion. 


\section{References}

1 Fisch P, Handgretinger R, Schaefer HE: Pure red cell aplasia. Br J Haematol 2000;111:1010-1022.

$>2$ Sawada K, Hirokawa M, Fujishima N: Diagnosis and management of acquired pure red cell aplasia. Hematol Oncol Clin North Am 2009;23:249-259.

-3 Helbig G, Stella-Holowiecka B, Wojnar J, et al: Pure red-cell aplasia following major and bi-directional ABO-incompatible allogeneic stem-cell transplantation: recovery of donor-derived erythropoiesis after long-term treatment using different therapeutic strategies. Ann Hematol 2007;86:677-683.

4 Deotare UR, Vishwabandya A, Mathews V, et al: Response to high-dose dexamethasone for acquired pure red cell aplasia following ABO-mismatched allogeneic stem cell transplantation. Bone Marrow Transplant 2006;37:1149-1150.

-5 Roychowdhury DF, Linker CA: Pure red cell aplasia complicating an ABO-compatible allogeneic bone marrow transplantation, treated successfully with antithymocyte globulin. Bone Marrow Transplant 1995;16:471-472.

-6 Sahovic EA, Flick J, Graham CD, et al: Case report: isoimmune inhibition of erythropoiesis following ABOincompatible bone marrow transplantation. Am J Med Sci 1991;302:369-373.

$>7$ Gmur JP, Burger J, Schaffner A, et al: Pure red cell aplasia of long duration complicating major ABOincompatible bone marrow transplantation. Blood 1990;75:290-295.

8 Ohta S, Yokoyama H, Ise T, et al: Apheresis therapy for prolonged red cell aplasia after major ABOmismatched bone marrow transplantation. Intern Med 1997;36:487-491.

-9 Heyll A, Aul C, Runde V, et al: Treatment of pure red cell aplasia after major ABO-incompatible bone marrow transplantation with recombinant erythropoietin. Blood 1991;77:906.

10 Bavaro P, Di Girolamo G, Olioso P, et al: Donor lymphocyte infusion as therapy for pure red cell aplasia following bone marrow transplantation. Br J Haematol 1999;104:930-931.

11 Yang MH, Hsu HC: Pure red cell aplasia after ABO-incompatible allogeneic stem cell transplantation in severe aplastic anemia with response to steroids: a case report and literature review. Ann Hematol 2001;80:299-301.

12 McLaughlin P, Grillo-Lopez AJ, Link BK, et al: Rituximab chimeric anti-CD20 monoclonal antibody therapy for relapsed indolent lymphoma: half of patients respond to a four-dose treatment program. J Clin Oncol 1998;16:2825-2833.

13 Zecca M, De Stefano P, Nobili B, et al: Anti-CD20 monoclonal antibody for the treatment of severe, immune-mediated, pure red cell aplasia and hemolytic anemia. Blood 2001;97:3995-3997.

14 Berentsen S: Rituximab for the treatment of autoimmune cytopenias. Haematologica 2007;92:15891596.

15 Maschan AA, Skorobogatova EV, Balashov DN, et al: Successful treatment of pure red cell aplasia with a single dose of rituximab in a child after major $\mathrm{ABO}$ incompatible peripheral blood allogeneic stem cell transplantation for acquired aplastic anemia. Bone Marrow Transplant 2002;30:405-407. 